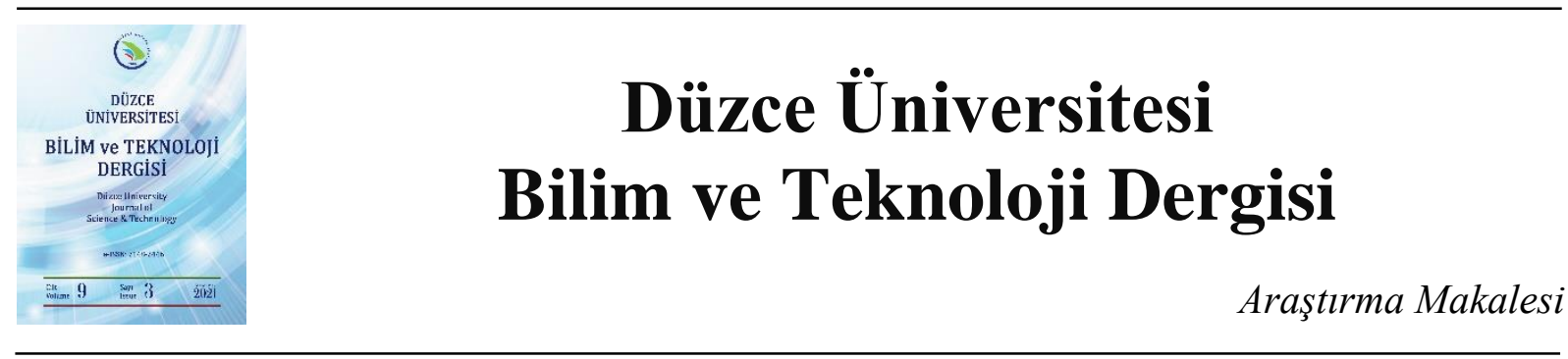

\section{İstanbul'da Sivrisinek Türleri ile İnvaziv Aedes Türlerinin Tespiti ve Bulunma Oranları}

\author{
(iD) Ali Rıza EDE ${ }^{\mathrm{a}}$, (D) Sevcan ÖZTEMİZ ${ }^{\mathrm{a}^{*}}$

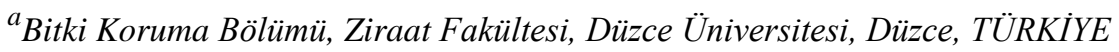 \\ * Sorumlu yazarin e-posta adresi: sevcanoztemiz@duzce.edu.tr \\ DOI:10.29130/dubited.868827
}

\begin{abstract}
ÖZET
Çalışmada İstanbul'un 27 ilçesinde (Avrupa yakasında Arnavutköy, Avcılar, Başakşehir, Beşiktaş, Beylikdüzü, Büyükçekmece, Çatalca, Esenler, Esenyurt, Eyüpsultan, Gaziosmanpaşa, Kağıthane, Küçükçekmece, Sarıyer, Silivri, Sultangazi, Anadolu yakasında Ataşehir, Beykoz, Kartal, Maltepe, Pendik, Sancaktepe, Sultanbeyli, Şile, Tuzla, Ümraniye, Üsküdar) sivrisinek türleri ile invaziv Aedes türleri (Diptera: Culicidae)'nin bulunma oranlarının belirlenmesi amaçlanmıştır. Çalışma, sivrisinek üreme kaynaklarından dipper aracılığıyla toplanan larva ve pupalardan elde edilen dişiler ile 1şık tuzaklarından elde edilen dişilerin tespiti ile yapılmış olup 2019 ve 2020 yıllarında yürütülmüştür. Çalışmada 4 cinse ait 13 sivrisinek türü belirlenmiştir. Toplam 247 üreme kaynağında bulunan sivrisinek türleri ve bulunma oranları, Culex pipiens L. \%45.4,Aedes albopictus (Skuse) \%20, Aedes cretinus (Edwards) \%9, Anopheles maculipennis kompleks (Anopheles sacharovi hariç) \%5.2 Culex territians \% 4 , Anopheles claviger (Meigen) \%2.8 Aedes vexans (Meigen) \%2.4, Culex theileri Theobald \%2.4, Culiseta annulata (Schrank)\%2, Culex hortensis Ficalbi\%1.6, Culex modestus Ficalbi\%1.6, Culex torrentium Martini\%2.4, Culiseta longiareolata (Macquart)\%1.2, Culex sp. (Diptera: Culicidae) olarak tespit edilmiştir. İstilacı tür olarak, Aedes albopictus(Skuse) ve Aedes cretinus(Edwards) saptanmıştır. Vektörlük potansiyelleri dikkate alındığında Ülkemizde yaygın hale gelen Aedes türleri ile mücadele programı oluşturulmalıdır.
\end{abstract}

Anahtar Kelimeler:Bulunma oranı, İnvaziv, İstanbul, Sivrisinek, Tür.

\section{Determination and Presence of Mosquito Species and Invasive Aedes Species in Istanbul}

\begin{abstract}
The aim of the study was to determine the incidence rates of mosquito species and invasive Aedes species in 27 districts of Istanbul (Arnavutköy, Avcılar, Başakşehir, Beşiktaş, Beylikdüzü, Büyükçekmece, Çatalca, Esenler, Esenyurt, Eyüpsultan, Gaziosmanpaşa, Kağıthane, Küçükçekmece, Sarıyer, Silivri, Sultangazi on the Anatolian side, Ataşehir, Beykoz, Kartal, Maltepe, Pendik, Sancaktepe, Sultanbeyli, Şile, Tuzla, Ümraniye, Üsküdar). It was found by determining females obtained from larvae and pupae collected by dipper from mosquito breeding sources and females obtained from light traps and was conducted in 2019 and 2020. In the study, 13 mosquito species belonging to 4 genera were determined. Mosquito species found in a total of 247 breeding sources and

their incidence were determined as Culex pipiens L. 45.4\%, Aedes albopictus (Skuse) 20\%, Aedes cretinus (Edwards) 9\%, Anopheles maculipennis complex (except Anopheles sacharovi) 5.2\% Culex territians 4\%, Anopheles claviger (Meigen) 2.8\%, Aedes vexans (Meigen) $2.4 \%$ Culex theileri Theobald $2.4 \%$, Culiseta annulata (Schrank)2\%, Culex hortensis Ficalbi1.6\%, Culex modestus Ficalbi 1.6\%Culex torrentium Martini2.4\%, Culiseta longiareolata (Macquart)1.2\%, Culex sp. (Diptera Culicidae). Aedes albopictus L. and Aedes cretinus (Skuse)
\end{abstract}

*Bu çalışma 'İstanbul'da Sivrisinek Türlerinin Belirlenmesi, Dağılımı ve Vektör Yetkinliğinin Araştırılması' isimli yüksek lisans tezinden türetilmiştir.

Geliş: 26/01/2021, Düzeltme: 18/03/2021, Kabul: 25/03/2021 
were identified as invasive species. Considering their vector potential a control program should be established against Aedes species, which have become widespread in our country.

Keywords:Incidence, Invasive, İstanbul, Mosquito, Species.

\section{GIRIS}

Sivrisinekler hastalık etmenlerini taşıma ve yayma özellikleri nedeniyle Dünya'da milyonlarca insan ve hayvan için tehdit oluşturmaktadır. Sivrisinekler virüs, nematod, bakteri, protozoa gibi patojenlere vektörlük yaparak, sıtma, filariasis, Dang Humması, Sarı Humma, Japon Ensefaliti, Zika ve Batı Nil Humması gibi hastalıklar nedeniyle her yıl milyonlarca insanın ölmesine sebep olurlar. Sivrisinekler 40'dan fazla cinse bağl1 3600 kadar türe sahip olup kutup bölgeleri hariç dünyanın hemen her yerine yayılmışlardır. Sivrisinekler zoocoğrafik bölgelerde bulunmaları, hızla çoğalmaları, fazlaca yumurta oluşturabilmeleri, aktif uçucu olmaları ve larvaların birçok üreme kaynağında yaşayabilmesi gibi nedenlerden dolayı vektör olarak önemlidir [1-6]. Dünya Sağlık Örgütü (WHO) tarafından milyonlarca insanın sivrisineklerin vektörlüğünü yaptığı hastalıklarla karşı karşıya kaldığını, 2017 yılında, 219 milyon sitma hastalığı olduğu ve tahmini sıtma ölüm sayısının 435.000 olduğu rapor edilmiştir [7].

Dang Humması, Zika hastalıkları taşıyan Aedes cinsi sivrisinekler invaziv özellikleri ve ciddi hastalıkları taşıması nedeni ile dikkat çekmektedir. İstanbul'un coğrafik konumu itibariyle deniz ve havayolu ulaşımlarının geçiş noktası olması, göçmen ve mülteci hareketliliği, turizm açısından tercih edilmesi, göçmen kuşların seyahat güzergâhında bulunması, küresel iklim değiş̧ikliğinden dolayı sivrisineklerin taşınmasını ve yayılmasını bu bölgede kolaylaştırmaktadır. Özellikle invaziv tür olan Aedes cinsi sivrisineklerin iklim şartlarına uyum sağlaması ve bazı bitki türlerinin kıtalar arası seyahat ile ithalatı ve araba lastiklerinin kontrolsüzlüğü dikkat çeken bu tür sivrisineğin jeopolitik öneme sahip İstanbul'da kolayca yayılabileceğinden ayrıca takip edilmesi ve izlenmesi önemlidir.

Söz konusu hastalık vektörlerinin hangi türler olduğu, halk sağlığı açısından üreme ve yayılış alanlarının belirlenmesi, hastalık takibinde ve sivrisinek mücadelesindeki başarıyı doğrudan etkileyebileceğinden bu çalışmada İstanbul'da sivrisinek türlerinin ve yayılım alanlarının belirlenmesi amaçlanmıştır.

\section{MATERYAL VE YÖNTEM}

Çalışmanın materyalini sivrisinek türleri, biyolojik dönemleri, dipper, 1şık tuzağı, yetiştirme kafesleri ve stereo mikroskop oluşturmuştur.

Arazi çalışmaları İstanbul'un 27 ilçesinde (Avrupa yakasında Arnavutköy, Avcılar, Başakşehir, Beşiktaş, Beylikdüzü, Büyükçekmece, Çatalca, Esenler, Esenyurt, Eyüpsultan, Gaziosmanpaşa, Kağıthane, Küçükçekmece, Sarıyer, Silivri, Sultangazi Anadolu yakasında Ataşehir, Beykoz, Kartal, Maltepe, Pendik, Sancaktepe, Sultanbeyli, Şile, Tuzla, Ümraniye, Üsküdar) 247 sivrisinek üreme kaynağından numune alınarak Haziran 2019 ve Aralık 2020 tarihleri arasında yürütülmüştür. Sivrisinek türleri, üreme kaynaklarından toplanan larva ve pupalardan elde edilen dişiler ile ışık tuzaklarından elde edilen dişilerin tespiti ile belirlenmiştir. Sivrisinek üreme kaynaklarından, larva ve pupalar dipper aracılığıyla toplanmıştır. Larva ve pupaların toplandığı lokaliteden tarih, adres, ilçe, çevre, habitatın niteliği, konum bilgisi kayıtları alınmıştır. Dere, göl, gölet vb. gibi sivrisinek üreme kaynaklarında numune alma işlemi birkaç farklı noktadan yapılmıştır. Dipper ile yüzeysel, kısmi yüzeysel, derin daldırma, içe dökülme gibi farklı yöntemler kullanılarak, özellikle suyun hareketsiz olduğu kenar kısımlarından aniden hızlı bir şekilde daldırarak larva numunesi alınmıştır. Dipper ile toplanan sivrisinek larva ve pupaları $500 \mathrm{ml}$ veya $1000 \mathrm{ml}$ 'lik plastik pet şişelere doldurulmuş ve hava girmesi için pet şişelerin kapakları delinmiştir. Numuneler sarsılmadan incelenmek üzere uygun koşullarda laboratuvara getirilmiştir. Larva ve pupaların numunelerin alındığı yere ait kayıt numarası yazılarak yetiştirme kafeslerine konulmuştur ve ergin hale geçmeleri sağlanmıştır [8,9]. Ergin sivrisinekleri yakalamak için 1şık tuzakları da kurulmuştur. Işık tuzakları sivrisinek üreme kaynaklarına en yakın 
mesafede, rüzgâr hızının az olduğu ve rüzgârın olmadığg $(2,06 \mathrm{~m} / \mathrm{s}$ aşmadığı) günlerde 1şığın az olduğu ortamlarda kurulmuştur. Işı1k tuzakları, akşam vakitlerinde hava kararmadan önce yerden ortalama 1-2 m yükseğe kurulmuş, sabah 09.30 gibi toplanmıştır. Işık tuzaklarının olduğu lokalitenin bitki örtüsü yoğunluğu, adres, konum, yerden yükseklik bilgileri kayıt edilmiştir. Tuzaklar içinden dişi sivrisinekler tür teşhisinde kullanılmak için plastik saklama kapları içerisinde alınmıştır [9,10]. Tür tanımlamaları stereo mikroskop altında larva ve erginlerin vücut kısımlarının morfolojisinden yararlanılarak ve kaynaklar yardımı [11-14] ile gerçekleştirilmiştir.

\section{BULGULAR}

Çalışma sivrisinek türlerini tespit etmek için Haziran 2019 ve Aralık 2020 tarihleri arasında İstanbul'un 27 ilçesinde yürütülmüştür. Larva ve pupa örnekleri 22 farklı habitat tipine (açık alanda su birikintisi, kapalı alanda su birikintisi, açık alanda su kanalı, kapalı alanda su kanalı, açık alanda 1zgara, kapalı alanda 1zgara, açık alanda kuyu, kapalı alanda kuyu, bidon, çeşme, depo, dere, havuz, inşaat, asansör boşluğundaki su birikintileri, fosseptik, saksı, sazlık, araba lastikleri, su sarnıçları, küvet, motopomp) ait 247 üreme kaynağından; 8804 adet larva, 328 adet pupa ve 453 adet dişi, 405 adet erkek ergin sivrisinek bireyleri toplanmıştır. Veriler larva ve pupadan yetiştirilerek ergin hale geçen dişi sivrisinekler ve 1şık tuzaklarıyla yakalanan dişi ergin sivrisinek bireylerden elde edilmiştir (Şekil 1). Tür teşhis sonuçlarına göre 4 cinse ait 13 sivrisinek türünün varlığ kaynağında bulunan sivrisinek türleri ve bulunma oranları, Culex pipiens L. \%45.4, Aedes albopictus (Skuse) \%20, Aedes cretinus (Edwards) \%9, Anopheles maculipennis kompleks (An. sacharovi hariç) $\% 5.2$, Culex territians \%4, Anopheles claviger(Meigen) \%2.8 Aedes vexans (Meigen) \%2.4, Culex theileri Theobald \%2.4,Culiseta annulata (Schrank)\%2, Culex hortensis Ficalbi\%1.6, Culex modestus Ficalbi\%1.6, Culex torrentium Martini\%2.4, Culiseta longiareolata (Macquart)\%1.2, Culex sp. (Diptera: Culicidae) olarak tespit edilmiştir.Çalışmada en yaygın bulunan türler arasında $C$. pipiens türü Şile ilçesi hariç tüm ilçelerde (toplam 26 ilçede), A. albopictus türü Sancaktepe ve Üsküdar ilçesi hariç tüm ilçelerde (toplam 25 ilçe) bulunmuştur. Bunu 12 ilçe (Arnavutköy, Beşiktaş, Beykoz, Eyüpsultan, Gaziosmanpaşa, Kağithane, Kartal, Küçükçekmece, Pendik, Sariyer, Tuzla, Ümraniye) ile A. cretinus türü, 8 ilçe ile A. maculipennis türü (Arnavutköy, Beykoz, Büyükçekmece, Çatalca, Eyüpsultan, Kağithane, Sariyer, Silivri), 7 ilçe (Arnavutköy, Avcılar,Büyükçekmece, Eyüpsultan, Pendik, Silivri, Şile) ile A. claviger türü ve 7 ilçe ile (Avcılar, Başakşehir, Beylikdüzü, Büyükçekmece, Eyüpsultan, Sarıyer, Silivri) C. territians türü takip etmiştir. En fazla tür sayısı Eyüpsultan (10 tür), Arnavutköy (8 tür) ve Sarıyer (8 tür) ilçelerinde, en az tür sayısı ise Üsküdar (1 tür) ilçesinde bulunmuştur. Türler daha çok sırası ile açık ve kapalı alan su birikintileri, bidon, havuz, dere, depo ve açık alan kanallardan toplanmıştır.

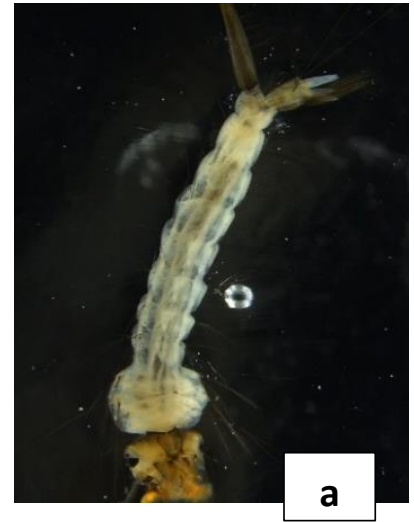

(a)

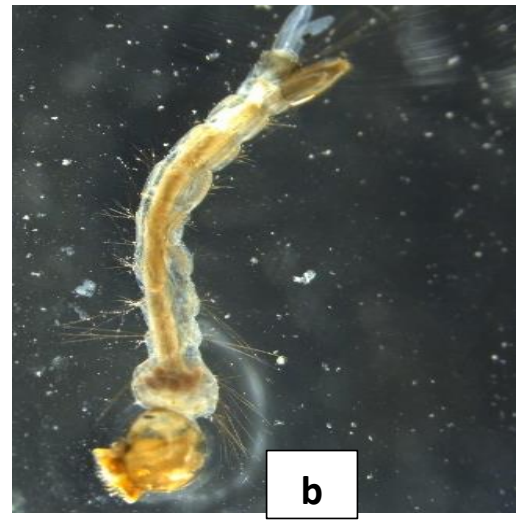

(b)

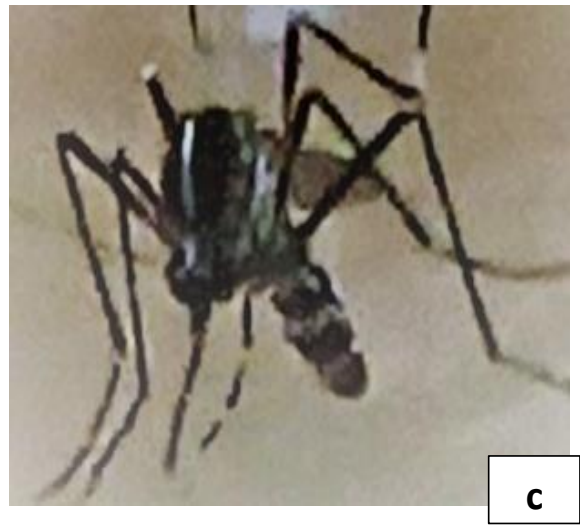

(c)

Şekil 1. Sivrisinek larva ve ergini (a) Culex pipiens larvası (b) Aedes cretinus larvası (c) Aedes sp. ergini 


\section{TARTISMA}

Sivrisinekler, Diptera takımına bağlı Culicidae familyası içinde yer alır. Dişi sivrisinekler insanlardan ve farklı konaklardan kan emerek beslenmelerini sağlarlarken konakçısına hastalık etmeninin bulaşmasını sağlarlar. Sivrisinekler taşıdıkları hastalıklar bakımından dünyada halk sağlığı için önemli bir tehdit oluşturmaktadır. Aedes aegypti (L.) Batı Nil virüsü, Dang virüsü, Sarı humma virüsü, chikungunya virüsü ve Zika virüsü hastalık etmenlerinin vektörlügünü yapmaktadır. Aedes aegypti (L.) küresel salgınlar açısından Zika virüsünü, kolay taşınabilmesi nedeniyle potansiyel risk taşımaktadır. Yaklaşık 216 milyon insan her yıl Zika virüsü'nün bulunduğu bölgelerden ABD'ye geçiş yapmaktadır. Yapılan bir çalışmada, A. aegypti türünün Doğu Karadeniz Bölgesi'nde bulunduğunu tespit edilmiştir $[15,20]$. Aedes albopictus(Skuse)'un kuvvetli bir istilacı olmasının ekosistem üzerindeki etkisinin yanı sıra insanlar için ölüm riski taşıyan Japon ensefaliti, Batı Nil ensefaliti, Chikungunya, Sarı Humma ve Dengue Humması gibi Flaviviridae, Bunyaviridae, Togaviridae familyalarına ait birçok arbovirüsün vektörü olması bu türün önemini daha da artırmaktadır. Aedes albopictus'un vektörlük yaptığ1 hastalıklar ile ilgili her yıl dünyanın farklı bölgelerinden milyonlarca vaka rapor edilmektedir. WHO'nun 2013 yılında yayınladığı rapora göre, dünya nüfusunun yarısı Dengue Humması'na yakalanma riski altındadır. $\mathrm{Bu}$ ateşli hastalıkların çok azına karşı aşı geliştirilmiş olup sadece semptomlara yönelik tedaviler kullanılmaktadır. Avrupa geneli için yapılan modellemeler, Türkiye'de Marmara Bölgesinin özellikle deniz kıyısı kısımlarının, tüm Trakya'nın, tüm Karadeniz kıyısı ve Doğu Akdeniz Bölgesi'nin A. albopictus açısından ideal yerleşim alanları olduğunu göstermiştir [16]. Aedes albopictus'un Trakya bölgesinde varlığı rapor edilmiştir [17]. Ülkemizde yapılan diğer bir çalışmada ise A. albopictus türünün Doğu Karadeniz Bölgesi'nin birçok yerinde bulunduğu rapor edilmiştir [15,18]. Mayıs-Ekim 2003 ve Mayıs-Ekim 2004 tarihleri arasında İstanbul'da bulunan sivrisinek türlerinin kompozisyonunu belirlemek için yapılan bir başka çalışmada, beş cinse ait sekiz sivrisinek türü tespit etmişlerdir [9]. Larva ve pupalardan yetiştirilen 1085 adet dişi sivrisineğin 992'si $(\% 91,43)$ Culex pipiens, 32'si $(\% 2,95)$ Culiseta longiareolata, 22'si (\%2,03) Anopheles maculipennis grubu (Anopheles sacharovi hariç), 18'i $(\% 1,66)$ Anopheles claviger, 13'ü $(\% 1,20)$ Culiseta annulata, 3’ü $(\% 0,28)$ Aedes vexans, 3’ü $(\% 0.28)$ Culex hortensis ve 2'si $(\% 0,18)$ Ochlerotatus caspius (Pallas) olduğu saptanmıştır. Işık tuzakları ile toplanan 78 adet dişi sivrisineğin tamamının Culex pipiensL. olduğu belirlenmiştir. Çalışmada $C$. pipiens'e 14 habitat tipinin hepsinde rastlanırken A. claviger'e 6 , Anopheles maculipennis grubuna (Anopheles sacharovi hariç) 5, Culiseta longiareolata'ya 3, Aedes vexans'a, Culiseta annulata ve $O$. caspius'a 2 ve Culex hortensis'e bir habitat tipinde rastlanmıştır [21]. Larvaların tür kompozisyonu ve aylık dağılımı ile ilgili 2003-2007 yılları arasında yapılan bir başka çalışmada, sivrisinek (Culicidae) 15 farklı potansiyel larva yaşama ortamından alınan toplam 293655 adet larva ve 1701 farklı örnek incelenmiş ve Culex, Anopheles, Aedes, Ochlerotatus ve Culiseta olmak üzere 21 tür tespit edilmiştir. Türlerin 2003 ile 2007 yılları arasında giderek azaldığını ve Temmuz ayında en yüksek seviyede olurken, Ekim ayında sayısının azaldığını, \%91 oranında C.pipiens' in baskın tür olduğu rapor edilmiştir [19].

Bu çalışmada Culex pipiens L. türü \%45,4 olarak tespit edilirken benzer konuda yürütülen diğer çalışmalarda bu oran \% 100ve \%91 oranında tespit edilmiştir. Aedes albopictus (Skuse) türüne \%20 oranında rastlanırken benzer diğer çalışmalarda ise bu türe rastlanmamıştır. Benzer şekilde Aedes cretinus (Edwards) türüne $\% 9$ oranında rastlanırken diğer çalışmalarda rastlanmamıştır $[19,21]$. Türkiye iklimsel özelliklerinin uygunluğu ve coğrafik konumu ile Güney Afrika ve Amerika'dan Avrupa' ya hızla yayılmakta olan sivrisinek türleri ve bulaştırdığı hastalıklar açısından büyük risk altında bulunmaktadır [22]. Ülkemizde sıtma, Batı Nil hastalığı görülmekle birlikte, Ülkemizde henüz varlığ1 bilinmeyen invaziv Aedes türlerinin taşıdığı dang humması, chikungunya virüsü ve zika virüs infeksiyonunun hızla Avrupa'ya yayılmasıyla, bu hastalıklar açısından risk altındadır [23]. Bu hastalıkların ticaret, seyahat gibi etkenler ile yakın zamanda görülmesi muhtemeldir. 


\section{V.SONUC}

Çalışmada; İstanbul'un 27 ilçesinde Culex pipiens L.'e 26 ilçede 112 lokasyonda, Aedes albopictus (Skuse) 25 ilçede 49 lokasyon, Aedes cretinus (Edwards) 12 ilçede 22 lokasyon, Anopheles maculipennis kompleks (s.1.) 8 ilçede 13 lokasyon, Anopheles claviger (Meigen) 7 ilçede 7 lokasyon, Culex territians 7 ilçede 10 lokasyon, Culiseta annulata (Schrank) 5 ilçede 5 lokasyon, Aedes vexans (Meigen) 4 ilçede 6 lokasyon, Culex hortensis Ficalbi 4 ilçede 4 lokasyon, Culex modestus Ficalbi 4 ilçede 4 lokasyon, Culex theileri Theobald 4 ilçede 6 lokasyon, Culex torrentium Martini 3 ilçede 6 lokasyon, Culiseta longiareolata (Macquart) 3 ilçede 3 lokasyonda saptanmıştır.

İstilacı türlerden, Aedes albopictus (Skuse) ve Aedes cretinus (Edwards)'a rastlanmıştır. En fazla görülen sivrisinek türü \%45.4 ile Culex pipiens L. bulunmuştur. Bu türü sırası ile \%20 Aedes albopictus (Skuse) ve $\% 9$ Aedes cretinus (Edwards), \%5,2Anopheles maculipennis kompleks (An. sacharovi hariç), \%4Culex territians, \%2.8Anopheles claviger (Meigen), \%2.4 Aedes vexans (Meigen), \%2.4 Culex theileri Theobald,\%2 Culiseta annulata (Schrank), \%1.6 Culex hortensis Ficalbi, \%1.6Culex modestus Ficalbi, \%2.4Culex torrentium Martini, \%1.2 Culiseta longiareolata (Macquart) türü takip etmiştir. Çalışmada en yaygın bulunan türler arasında $C$. pipiens türü (26 ilçe) ve A. albopictus türü(25 ilçe) hemen hemen tüm ilçelerde bulunmuştur. Bunu 12 ilçe ile A. cretinus türü, 8 ilçe ile $A$. maculipennis türü 7 ilçe ile A. clavigerve $C$. territians türü takip etmiştir. En fazla tür sayısı Eyüpsultan (10 tür), Arnavutköy ( 8 tür) ve Sarıyer (8 tür) ilçelerinde, en az tür sayısı ise Üsküdar (1 tür) ilçesinde bulunmuştur. Türler daha çok sırası ile açık ve kapalı alan su birikintileri, bidon, havuz, dere, depo ve açık alan kanallardan toplanmıştır. Vektörlük potansiyelleri dikkate alındığında sivrisinekler ile mücadelenin önemi ortaya çıkmaktadır. Bu mücadelede başarı sağlamak için kültürel ve fiziksel mücadele ön plana çıkarılmalıdır. Ülkemizde yaygın hale gelen Aedes türleri ile ilgili mücadele programı oluşturulmalıdır. Oluşturulacak mücadele yönetimine insanların da dâhil edilerek farkındalık oluşturulmalı ve mücadelenin etkinliği arttırılmalıdır.

TEŞEKKÜR: Arazi çalışmalarında destek olan İstanbul Büyükşehir Belediyesi (IBB) Sağlık Daire Başkanlığı, Sağlık ve Hıfzıssıhha Müdürlüğ̈̈’ne bağlı Vektörlerle Mücadelesi Birimi ekiplerine teşekkür ederiz.

\section{KAYNAKLAR}

[1] B. Alten ve S. S. Çağlar, ,Vektör Ekolojisi ve Mücadelesi, 1. bask1, Ankara, Türkiye: Sağl1k Bakanlığı, 1998, ss. 249.

[2] B. J. Beaty ve W. C. Marquardt, The Biology of Disease Vectors, Chicago, ABD: University Press Of Colorado, 1996, ss. 450.

[3] R. E. Harbach ve L. J. Kitching, "Reconsideration of anopheline mosquito phylogeny (Diptera: Culicidae: Anophelinae) based on morphological data," Syst Biodiversit, c .3, s. 4, ss. 345-374, 2005.

[4] G. Wang, C. Li, X. Guo, , D. Xing, Y. Dong, Z. Wang, Y. Zhang, M. Liu, Z. Zheng, H. Zhang, X. Zhu, Z. Wu ve T. Zhao, "Identifying the main mosquito species in China based on DNA barcoding," Plos One, c. 7,ss. 1-11, 2012.

[5] R. Wilkerson, Y-M. Linton, D. Fonseca, T. Schultz, D. Price ve D. Strickman, "Making mosquito taxonomy useful: a stable classification of tribe aedini that balances utility with current knowledge of evolutionary relationships," Plos One, c. 7, s. 10, ss. 1-26, 2015. 
[6] G. Benelli, "Spreas of Zika Virus: the key role of mosquito vector control," Asian Pasific Journal of Tropical Biomedicine, c. 6, ss. 468-471, 2016.

[7] Anonim. (2019, 9 Aralık). World Health Organization 2017 Global malaria report, Geneva, Switzerland. [Online]. Erişim:https://www.who.int/malaria/publications/world-malaria-report2017/en/

[8] N. Becker, D. Petric, M. Zgomba, C. Boase, C. Dahl, J. Lane ve A. Kaiser, Mosquitoes and Their Control, London, England: Kluwer Academic/Plenum Publishers, London, 2003, ss. 498.

[9] K. Öter, "İstanbul'da görülen sivrisinek türlerinin tespiti," Doktora tezi, Parazitoloji, Sağlik Bilimleri Enstitüsü, İstanbul Üniversitesi, İstanbul, Türkiye, 2007.

[10] B. Alten, S. S. Çağlar ve N. Özer, "Malaria and its Vectors in Turkey," European Mosquito Bulletin, c. 7, ss. 27-33, 2000.

[11] N. Becker, D. Petric, M. Zgomba, C. Boase, M. Madon, C. Dahl ve A. Kaiser, Mosquitoes and Their Control, 2. Edition, New York, USA: Springer, Heidelberg, New York, 2010, ss. 577.

[12] R. F. Darsie ve A. Samanidou-Voyadjoglou, 'Keys for the identification of the mosquitoes of Greece,', Journal of the American Mosquito Control Association, c. 7, ss. 247-254, 1997.

[13] A. Merdivenci, Türkiye Sivrisinekleri, İstanbul, Türkiye: İstanbul Üniversitesi Cerrahpaşa Tıp Fakültesi Yayınları, 1984, ss. 355.

[14] E. Schaffner, G. Angel, B. Geoffroy, J. P. Hervy, A. Rhaiem ve J. Brunhes, The Mosquitoes of Europe (CD-Rom), Montpellier, France:Institute de Resherche Pour le Développement (IRD), 2001.

[15] M. M. Akiner, B. Demirci, G. Babuadze, V. Robert ve F. Schaffner, "Spread of the invasive mosquitoes Aedes aegypti and Aedes albopictus in The Black Sea Region increases risk of Chikungunya, Dengue, and Zika Outbreaks in Europe," PLOS Neglected Tropical Diseases, 2016, ss. 1-5.

[16] S. Cunze, L. K. Koch, J. Kochmann ve S. Klimpel, "Aedes albopictus and Aedes japonicus two invasive mosquito species with different temperature niches in Europe," Parasit And Vectors, c. 9, ss. $573,2016$.

[17] K. Oter, F. Gunay, E. Tuzer, Y. M. Linton, R. Bellini ve B. Alten, "First record of Stegomyia Albopicta in Turkey determined by active ovitrap surveillance and DNA barcoding,"Vector Borne Zoonotic Dis, c. 13, ss. 753-761, 2013.

[18] M. Doğan, "Vektör sivrisinek türü Aedes albopictus (Diptera: Culicidae)'un yaşam öyküsü karakterleri üzerine çalışmalar," Yüksek lisans tezi, Biyoloji, Fen Bilimleri Enstitüsü, Hacettepe Üniversitesi, Ankara, Türkiye, 2015.

[19] A. Z. Şengil, H. Akkaya, M. Gönenc, D. Gönenc ve D. Özkan, "Species composition and monthly distribution of Mosquito (Culicidae) larvae in the Istanbul Metropolitan Area, Turkey," Turkey.Int. J. Biol.Med., c. 2, ss. 415-424, 2011.

[20] E. Polat, S. M. Altınkum, F. Y1lmaz, S. Turan-Uzuntaş ve Y. Bağdatlı, "İstanbul'un sivrisinek faunası ve Culex Pipiens larvalarının Bacillus cinsi bakterilere karşı duyarlılı̆̆ı," Turk Hij Den Biyoloji Dergisi, c. 73, ss. 149-56, 2016.

[21] K. Öter ve E. Tüzer, "İstanbul'da sivrisinek türlerinin (Diptera: Culicidae) kompozisyonu," İstanbul Üniversitesi Veterinerlik Fakültesi Dergisi, c. 40, s. 2, ss. 249-259, 2014. 
[22] Anonim. (2019, 13 Aral1k). European Centre for Disease Prevention and Control, [Online]. Erişim: https://www.ecdc.europa.eu/en/disease-vectors/surveillance-and-disease-data/mosquito-maps.

[23] Anonim. (2019, 13 Aral1k). European Centre for Disease Prevention and Control, [Online]. Erişim: https://www.ecdc.europa.eu/en/disease-vectors/facts/mosquito-factsheets/aedes-aegypti. 